\title{
Effects of Pressure Heads and Soil Bulk Density on Infiltration Characteristics of Vertically Inserted Moistube Irrigation
}

\author{
Youliang Peng, Xiaogang Liu*, Yifei Zhu, Qiliang Yang \\ Faculty of Agricultural and Food, Kunming University of Science and Technology, Kunming 650500, China
}

Corresponding Author Email: liuxiaogangjy@ 126.com

https://doi.org/10.18280/eesrj.060304

Received: 16 May 2019

Accepted: 27 July 2019

\section{Keywords:}

moistube irrigation, pressure head, soil bulk density, infiltration rate, cumulative infiltration, regression analysis

\begin{abstract}
Moistube irrigation is a new water-saving technology. In order to explore the effect of pressure head and soil bulk density on water infiltration of moistube irrigation in vertical inserting mode, a series of indoor infiltration experiments were performed. Three pressure heads $\left(\mathrm{H}_{1}: 1.0 \mathrm{~m}, \mathrm{H}_{2}: 1.5 \mathrm{~m}\right.$ and $\left.\mathrm{H}_{3}: 2.0 \mathrm{~m}\right)$ and three soil bulk densities $\left(\mathrm{D}_{1}: 1.00 \mathrm{~g} \cdot \mathrm{cm}^{-3}, \mathrm{D}_{2}: 1.15 \mathrm{~g} \cdot \mathrm{cm}^{-}\right.$ ${ }^{3}$ and $\mathrm{D}_{3}: 1.30 \mathrm{~g} \cdot \mathrm{cm}^{-3}$ ) were set, with a total of 9 treatments, each processing 3 replicates. Wetting body was selected as observation object to record the change of wetting front profile. During the infiltration process, the Mariotte bottle was recorded and the wetting front at each time point was depicted on the side of the soil box. After $124 \mathrm{~h}$ of infiltration, the contours of wetting front at each time point depicted on the side of the soil box were copied onto the checkerboard to calculate the soil wetting volume, and the cumulative infiltration was calculated according to the Mariotte bottle scale and inner diameter. Studying the relationship between wetting volume, infiltration rate and cumulative infiltration with infiltration time, and the impacts of pressure head and soil bulk density on infiltration coefficient $K$ and infiltration index $\alpha$. The results showed that the pressure head and soil bulk density had significant effects on the infiltration capacity of moistube irrigation. Compared with $\mathrm{D}_{1}$, steady infiltration rates and cumulative infiltration of moistube irrigation decreased by $14.27 \%-33.61 \%$ and $12.92 \%$ $30.54 \%$ with the increase of soil bulk density. Compared with $\mathrm{H}_{1}$, steady infiltration rate and cumulative infiltration of moistube irrigation increased by $17.12 \%-37.02 \%$ and $18.67 \%$ $40.31 \%$ with the increase of pressure head. The wetted soil volume decreased with the increase of soil bulk density, while increased with the increase of pressure head. The changing process of cumulative infiltration with time was accorded with Kostiakov model. The infiltration coefficient $K$ was positively correlated with pressure head and negatively correlated with soil bulk density, while the infiltration index $\alpha$ was negatively correlated with pressure head and positively correlated with the soil bulk density. Regression analysis showed that the influence of pressure head on infiltration index $\alpha$ was greater than soil bulk density, and the influence of pressure head on infiltration coefficient $K$ was less than soil bulk density. The water infiltration capacity of moistube irrigation increased with the increase of pressure head, while decreased with the increase of soil bulk density. The results can provide a scientific basis for the practical application of moistube irrigation in agriculture.
\end{abstract}

\section{INTRODUCTION}

Moistube irrigation (MI) is a new technology in the field of agriculture developed by using semi-permeable membrane technology [1-3]. Compared with other irrigation methods, MI has smaller head loss, and the flow index is larger [4-5]. Compared with surface irrigation technology, MI can reduce surface evaporation and soil deep leakage, and has the advantages of water saving. At the same time, it also has the characteristics of strong anti-clogging performance, low operating cost and improving soil environment in crop root zone [6-11].

The MI outflow is mainly affected by pressure head, soil bulk density and soil texture [12]. Pressure head, as one of the main driving forces of MI, is an important factor affecting water infiltration [13-14], and plays a significant role in MI. the soil wetting volume, cumulative infiltration, average infiltration rate, horizontal wetting front of soil and vertical migration distance will increase with the increase of pressure head [15-17]. Soil bulk density has a great influence on soil physical properties and erosion resistance. With the increase of soil bulk density, the greater the infiltration resistance of water in soil, the smaller the soil wetting volume and diffusion coefficient $[6,12,19]$. As a new water saving technology, MI is more focused on horizontal layout, while the infiltration law of vertical MI suitable for fruit trees and economic trees with wide distance crops is still insufficiency.

In order to further clarify the water infiltration characteristics of vertical MI, the method of laboratory simulation test was adopted to study the effects of pressure head and soil bulk density on the infiltration characteristics of vertical wetting irrigation so as to provide scientific basis for rational use of moistube. 


\section{MATERIALS AND METHODS}

\subsection{Experimental materials}

The obtained soil samples were air-dried, compacted and evenly mixed, and then passed through a $2 \mathrm{~mm}$ sieve. Soil particle size distribution was analyzed and determined using laser particle size analyzer (Mastersizer-2000, UK). The particle size composition of soil natural heap laying down was $0.050 \mathrm{~mm}<\mathrm{d}<2.000 \mathrm{~mm}, 0.002 \mathrm{~mm}<\mathrm{d}<0.050 \mathrm{~mm}$ and $\mathrm{d}<0.002 \mathrm{~mm}$, accounting for $16.80 \%, 28.63 \%$ and $54.57 \%$ of the total soil sample, respectively. Soil type was determined to be clay loam according to the international soil classification system, its initial moisture content was $3.78 \%$.

\subsection{Experimental device}

The test device is mainly composed of soil box, moistube, rubber hose, Mariotte bottle and lifting support. The soil box (40 $\mathrm{cm} \times 40 \mathrm{~cm} \times 45 \mathrm{~cm}$ ) was used to fill the soil sample for testing. The 3rd generation moistube (Shenzhen Moistube Irrigation Co., Ltd, China) is a polymer semi-permeable membrane with inner layer thickness of $0.06 \mathrm{~mm}$ and micropore diameter ranging from 10 to $900 \mathrm{~nm}$. The arrangement of moistube is vertical, the upper end was connected with rubber hose, and the lower end is closed by rubber plug. Rubber hoses was used to connect moistube and Mariotte bottle. The Mariotte bottle is used to provide a constant head of water with a scale on it to calculate the cumulative infiltration. Lifting bracket realizes water head regulation.

\subsection{Experimental design and method}

Three pressure heads and three soil bulk densities were set in the experiment. The three pressure heads were $\mathrm{H}_{1}: 1.0 \mathrm{~m}$, $\mathrm{H}_{2}: 1.5 \mathrm{~m}$ and $\mathrm{H}_{3}: 2.0 \mathrm{~m}$, respectively. Three soil bulk densities were $\mathrm{D}_{1}: 1.00 \mathrm{~g} \cdot \mathrm{cm}^{-3}, \mathrm{D}_{2}: 1.15 \mathrm{~g} \cdot \mathrm{cm}^{-3}$ and $\mathrm{D}_{3}: 1.30 \mathrm{~g} \cdot \mathrm{cm}^{-3}$, respectively. This experiment consisted of 9 treatments in total, and each treatment was repeated three times. The length of moistube was $30 \mathrm{~cm}$ and the effective seepage length was 25 $\mathrm{cm}$. The moistube was vertically inserted into the plexiglass soil box, its upper end was $5 \mathrm{~cm}$ away from the soil surface, and the horizontal distance between the two sides and the two walls of plexiglass soil box was $1 \mathrm{~cm}$. The filling height of plexiglass soil box was $40 \mathrm{~cm}$. During the process of infiltration, Mariotte bottle readings were recorded every $2 \mathrm{~h}$ during the first 12 hours of infiltration, once every $4 \mathrm{~h}$ from 12 hours to 48 hours, once every $8 \mathrm{~h}$ after that, and wetting fronts at each point of time were depicted on the side of soil box. After 124 hours of infiltration, the experiment was completed. The cumulative infiltration and infiltration rate were calculated according to Mariotte bottle calibration scale and the inner diameter. The infiltration rate is the cumulative infiltration amount per unit time.

The wetting front migration curve and the volume of the rotating body were used to calculate the volume of the wetting body at different time, and the formula should be as Eq. (1):

$$
V=\frac{1}{4} \pi \int_{0}^{a} f^{2}(x) d x
$$

where, $V$ is the soil wetting volume, $\mathrm{cm}^{3} ; a$ is the maximum depth of wetting front, $\mathrm{cm} ; f(\mathrm{x})$ is the fitting function of wetting front migration, and the correlation coefficient with measured curve is more than 0.9 .

$$
f(x)=\sum_{i=0}^{n} b_{i} x^{i}
$$

where, $x$ is the depth of the wetting front, $\mathrm{cm} ; b_{\mathrm{i}}$ is the fitting coefficient of $f(\mathrm{x}) ; n$ is a positive integer.

\section{RESULTS}

\subsection{Effect of pressure head and soil bulk density on wetting volume}

The relationship between soil wetting volume and infiltration time was simulated by quadratic polynomial, and the absolute coefficients were greater than 0.99 (Table 1). Compared with the measured soil wetting volume, after infiltrating 24 hours, the relative error of the simulated values ranged from $0.24 \%$ to $6.11 \%$, with an average of $2.56 \%$, while the average relative error was only $1.64 \%$ and $1.54 \%$ after 48 hours and 124 hours of infiltration. It indicated that the simulation result was better, and the quadratic polynomial of infiltration time could well describe the change process of wetting volume in vertical moistube irrigation (MI). The soil wetting volume decreased with the increase of soil bulk density under the same pressure head and infiltration time, but increased with the increase of pressure head at the same soil bulk density and infiltration time.

\begin{tabular}{|c|c|c|c|c|c|c|c|c|c|c|c|c|}
\hline \multirow{2}{*}{ Pressure head } & \multirow{2}{*}{ Soil bulk density } & \multirow{2}{*}{ Fitting formula } & \multirow{2}{*}{$R^{2}$} & \multicolumn{3}{|c|}{ Measured value $\left(\mathrm{cm}^{3}\right)$} & \multicolumn{3}{|c|}{ Simulation value $\left(\mathrm{cm}^{3}\right)$} & \multicolumn{3}{|c|}{ Relative error(\%) } \\
\hline & & & & $24 \mathrm{~h}$ & $48 \mathrm{~h}$ & $124 \mathrm{~h}$ & $24 \mathrm{~h}$ & $48 \mathrm{~h}$ & $124 \mathrm{~h}$ & $24 \mathrm{~h}$ & $48 \mathrm{~h}$ & $124 \mathrm{~h}$ \\
\hline \multirow{3}{*}{$\mathrm{H}_{1}$} & $\mathrm{D}_{1}$ & $V=-0.51 t^{2}+156.06 t+31.06$ & 0.9995 & 3486.77 & 6382.05 & 11651.74 & 3478.31 & 6329.171 & 11422.35 & 0.24 & 0.83 & 1.97 \\
\hline & $\mathrm{D}_{2}$ & $V=-0.17 t^{2}+86.40 t-43.15$ & 0.9976 & 1847.36 & 3564.20 & 8023.62 & 1929.44 & 3699.85 & 7972.34 & 4.44 & 3.81 & 0.64 \\
\hline & $\mathrm{D}_{3}$ & $V=-0.12 t^{2}+58.15 t+30.74$ & 0.9994 & 1321.50 & 2445.29 & 5307.28 & 1356.00 & 2540.14 & 5358.90 & 2.61 & 3.88 & 0.97 \\
\hline \multirow{3}{*}{$\mathrm{H}_{2}$} & $\mathrm{D}_{1}$ & $V=-0.55 t^{2}+190.76 t-220.98$ & 0.9986 & 4082.58 & 7671.22 & 14926.15 & 4034.87 & 7645.951 & 14827.31 & 1.17 & 0.33 & 0.66 \\
\hline & $\mathrm{D}_{2}$ & $V=-0.17 t^{2}+91.54 t+79.58$ & 0.9994 & 2212.01 & 4032.91 & 8725.12 & 2176.65 & 4073.50 & 8759.31 & 1.60 & 1.01 & 0.39 \\
\hline & $\mathrm{D}_{3}$ & $V=-0.24 t^{2}+83.98 t+199.20$ & 0.9965 & 2058.98 & 3682.12 & 7125.79 & 2075.95 & 3675.07 & 6907.35 & 0.82 & 0.19 & 3.07 \\
\hline \multirow{3}{*}{$\mathrm{H}_{3}$} & $D_{1}$ & $V=-0.41 t^{2}+173.5 t+135.71$ & 0.9972 & 4159.08 & 7701.38 & 15870.06 & 4059.86 & 7504.32 & 15247.14 & 2.39 & 2.56 & 3.93 \\
\hline & $\mathrm{D}_{2}$ & $V=-0.05 t^{2}+93.91 t+212.72$ & 0.9990 & 2352.27 & 4568.86 & 10958.85 & 2438.96 & 4609.90 & 11119.76 & 3.69 & 0.90 & 1.47 \\
\hline & $\mathrm{D}_{3}$ & $V=-0.31 t^{2}+107.81 t-137.18$ & 0.9993 & 2137.46 & 4362.55 & 8430.33 & 2268.01 & 4308.71 & 8366.29 & 6.11 & 1.23 & 0.76 \\
\hline
\end{tabular}

Table 1. Wetted soil volume under different pressure heads and soil bulk densities

Notes: $V$ : soil wetting volume, $\mathrm{cm}^{3} ; t$ : Infiltration time, $\mathrm{h}$. 


\subsection{Effect of pressure head and soil bulk density on infiltration rate}

Figure 1 showed that the infiltration rate was relatively high within 24 hours of the beginning of infiltration, but decreased rapidly. Then the infiltration rate gradually approached stable with the infiltration time, and reached stability after 48 hours. Pressure head and soil bulk density had significant effects on steady infiltration rate. Compared with $\mathrm{H}_{1}$, the steady infiltration rates of $\mathrm{H}_{2}$ and $\mathrm{H}_{3}$ increased by $17.13 \%-25.47 \%$ and $28.25 \%-37.02 \%$ respectively. Compared with $\mathrm{D}_{1}$, the steady infiltration rate of $\mathrm{D}_{2}$ and $\mathrm{D}_{3}$ decreased by $14.27 \%$ $19.75 \%$ and $28.89 \%-33.62 \%$ respectively. Therefore, the steady infiltration rate enhanced with the increase of pressure head, but decreased with the increase of soil bulk density.

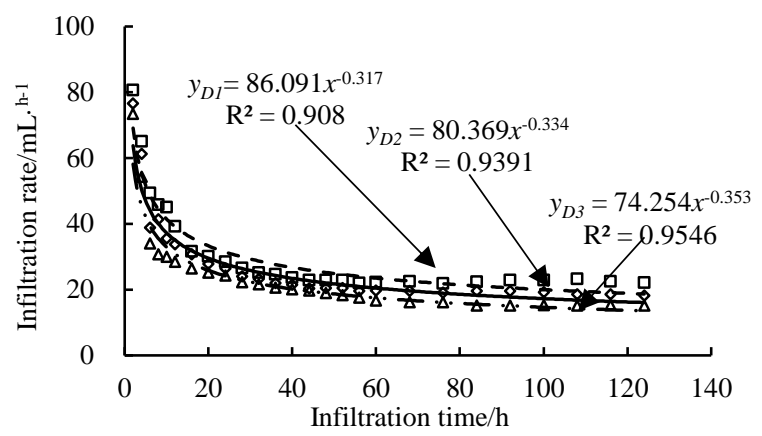

(a) $\mathrm{H}_{1}$

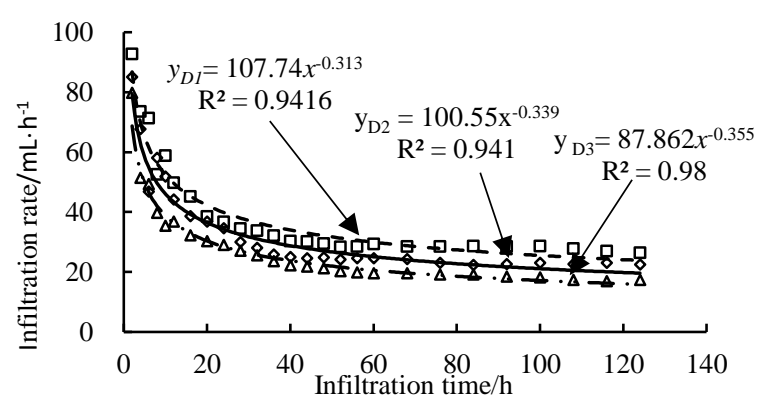

(b) $\mathrm{H}_{2}$

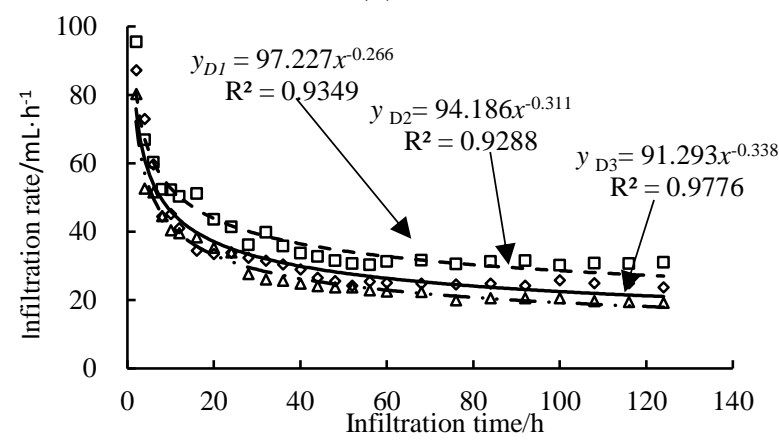

(c) $\mathrm{H}_{3}$

Figure 1. Curve between infiltration rate and time under different pressure heads and soil bulk densities

\subsection{Effect of pressure head and soil bulk density on cumulative infiltration}

Accumulated infiltration is often used to characterize infiltration capacity before reaching a stable infiltration rate [20]. The absolute coefficients of power function fitting of cumulative infiltration and infiltration time were greater than 0.9 (Figure 2). The experimental results showed that the cumulative infiltration increased with the increase of infiltration time under the same water head and soil bulk density. After $128 \mathrm{~h}$ infiltration, the cumulative infiltration of $\mathrm{H}_{2}$ and $\mathrm{H}_{3}$ increased by $18.67 \%-26.47 \%$ and $30.49 \%-$ $40.31 \%$ respectively when compared with $\mathrm{H} 1$. Compared with $\mathrm{D}_{1}, \mathrm{D}_{2}$ and $\mathrm{D}_{3}$ decreased the cumulative infiltration by $12.92 \%-18.97 \%$ and $25.31 \%-30.54 \%$ respectively. The results indicated infiltration rate increased with pressure head, but decreased with soil bulk density.

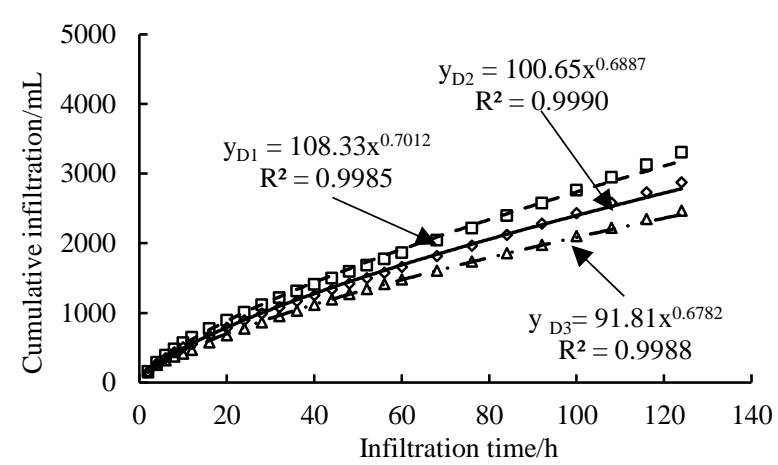

(a) $\mathrm{H}_{1}$

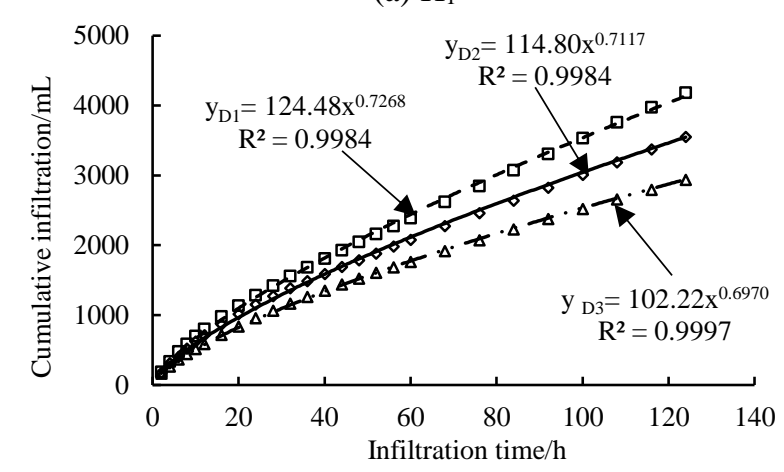

(b) $\mathrm{H}_{2}$

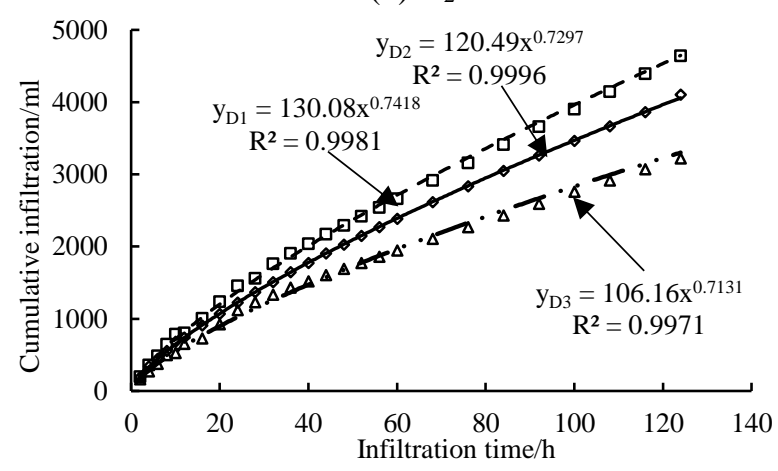

(c) $\mathrm{H}_{3}$

Figure 2. Curve between cumulative infiltration and time under different pressure heads and soil bulk densities

\subsection{Effect of pressure head and soil bulk density on infiltration model parameters}

The infiltration process was described by Kostiakov soil infiltration model. Although the model is an empirical model, the parameters could also repress some characteristics of soil infiltration. The formulas for calculating infiltration rate and cumulative infiltration amount are should be as [21]:

$$
\begin{gathered}
i_{t}=i_{1} t^{-\alpha} \\
I_{t}=\int_{0}^{t} i_{t} d t=\int_{0}^{t} i_{1} t^{-\alpha} d t=\frac{i_{1}}{1-\alpha} t^{1-\alpha}=K t^{1-\alpha}
\end{gathered}
$$


where, $i_{\mathrm{t}}$ is the infiltration rate, measured by the thickness of water layer per unit time $\left(\mathrm{cm} \cdot \mathrm{h}^{-1}\right) ; i_{1}$ is the infiltration rate at the end of the first unit time; $t$ is the infiltration time (h); $\alpha$ is the infiltration index, reflecting the attenuation rate of soil infiltration capacity; $I_{\mathrm{t}}$ is the cumulative infiltration amount at $\mathrm{t}$ time $(\mathrm{cm}) ; K$ is the infiltration coefficient $\left(\mathrm{cm} \cdot \mathrm{h}^{-1}\right)$, reflecting the cumulative infiltration at the end of the first unit period after infiltration.

By fitting and analyzing the data processed in this experiment, the results showed that the absolute coefficients were above 0.99 (Table 2). The infiltration index $\alpha$ decreased with the increase of pressure head, and the infiltration coefficient $K$ increased with the increase of pressure head (Table 2). Compared with $\mathrm{H}_{1}$, the $\alpha$ values of $\mathrm{H}_{2}$ and $\mathrm{H}_{3}$ decreased by $5.84 \%-8.57 \%$ and $10.85 \%-13.59 \%$, while the $K$ values increased by $11.34 \%-14.91 \%$ and $15.63 \%-20.08 \%$, respectively. When the pressure head was the same, the infiltration index $\alpha$ increased with the increase of soil bulk density, while the infiltration coefficient $K$ decreased with the increase of soil bulk density. Compared with $\mathrm{D}_{1}$, the $\alpha$ values of $\mathrm{D}_{2}$ and $\mathrm{D}_{3}$ increased by $4.18 \%-5.53 \%$ and $7.70 \%-11.12 \%$, while the $K$ values decreased by $7.09 \%-7.78 \%$ and $8.78 \%$ $11.90 \%$, respectively.

Table 2. Infiltration parameters under different pressure heads and soil bulk densities

\begin{tabular}{ccccc}
\hline $\begin{array}{c}\text { Pressure } \\
\text { head }\end{array}$ & $\begin{array}{c}\text { Soil bulk } \\
\text { density }\end{array}$ & $\begin{array}{c}\text { Pnfiltration } \\
\text { coefficient } K\end{array}$ & $\begin{array}{c}\text { Infiltration } \\
\text { index } \alpha\end{array}$ & $R^{2}$ \\
\hline \multirow{3}{*}{$\mathrm{H}_{1}$} & $\mathrm{D}_{1}$ & 108.33 & 0.2988 & 0.9985 \\
& $\mathrm{D}_{2}$ & 100.65 & 0.3113 & 0.999 \\
& $\mathrm{D}_{3}$ & 91.81 & 0.3218 & 0.9988 \\
$\mathrm{H}_{2}$ & $\mathrm{D}_{1}$ & 124.48 & 0.2732 & 0.9984 \\
& $\mathrm{D}_{2}$ & 114.80 & 0.2883 & 0.9984 \\
& $\mathrm{D}_{3}$ & 102.22 & 0.3030 & 0.9997 \\
$\mathrm{H}_{3}$ & $\mathrm{D}_{1}$ & 130.08 & 0.2582 & 0.9981 \\
& $\mathrm{D}_{2}$ & 120.49 & 0.2703 & 0.9996 \\
& $\mathrm{D}_{3}$ & 106.16 & 0.2869 & 0.9971 \\
\hline
\end{tabular}

\subsection{Regression analysis}

It was found that the infiltration index $\alpha$, as well as the infiltration coefficient $K$, were exponentially related to the pressure head and soil bulk density. The relationships could be expressed as:

$$
\begin{gathered}
K=A e^{B H+C D} \\
\alpha=G e^{E H+F D}
\end{gathered}
$$

where, $A, B, C, G, E$ and $F$ are coefficients; $K$ is infiltration coefficient, $\mathrm{cm} \cdot \mathrm{h}^{-1} ; \alpha$ is infiltration index; $H$ is pressure head, $\mathrm{m} ; D$ is soil bulk density, $\mathrm{g} \cdot \mathrm{cm}^{-3}$.

Logarithms were taken on both sides of formula (5) and (6) and the fitting model is obtained $\left(K=176.296 \mathrm{e}^{0.169 \mathrm{H}-0.629 \mathrm{D}}\right)$, $\left.\alpha=0.247 \mathrm{e}^{-0.134 \mathrm{H}+0.315 \mathrm{D}}\right)$. The determination coefficients $R^{2}$ were 0.96 and 0.99 , indicating good fitting effect.

T-test [22] was adopted to analyze the influence degree of various influencing factors on the cumulative infiltration. And the test value $\mathrm{t}$ was 2.776 when $\mathrm{a}=0.05$. The $t$ values of $B, C$, $E$ and $F$ were $7.576,-8.435,-18.050$ and 12.709 respectively, and the absolute values were all greater than 2.776. It showed that the effects of pressure head and soil bulk density on infiltration index $\alpha$ and coefficient $K$ were significant. The influence of pressure head on the infiltration index $\alpha$ was greater than that of the soil bulk density, while the influence of soil bulk density on the infiltration coefficient $K$ was greater than that of the pressure head. A value of $t$ greater than 0 indicates that the influencing factor is positively correlated with the infiltration index $\alpha$ and the infiltration coefficient $K$, otherwise it is negatively correlated. Therefore the infiltration index $\alpha$ was negatively correlated with pressure head but positively with soil bulk density. While the infiltration coefficient $K$ was positively correlated with the pressure head but negatively with the soil bulk density.

\section{DISCUSSION}

There are many factors affecting water infiltration in moistube irrigation, including salinity, pressure head, soil bulk density, initial soil moisture content, burial depth and so on [8, $12,15,23]$. In our study, the effects of pressure head and soil bulk density on water infiltration character in vertical moistube irrigation were studied. It is found that the cumulative infiltration, steady infiltration rate, soil wetting volume and infiltration coefficient $K$ increased with the increase of pressure head, while the infiltration index $\alpha$ decreased, which is basically consistent with the relevant research results $[12,15]$. However, $\mathrm{Ma}$ et al found that the infiltration coefficient $K$ increased firstly and then decreased with the increase of pressure head [24], which was not completely consistent with the results of our study. The pressure head (only 5-60 cm) was small in Ma's experiment. With the increase of pressure head, soil infiltration interface changed from compact to relatively stable, and finally to compact [24], so the infiltration coefficient $K$ increased first and then decreased. While the pressure head of this experiment was larger (1-2 m), which changed the condition of the soil at the infiltration interface, resulting in the increase of the infiltration coefficient $K$ with the increase of pressure head. This may because pressure head changed of soil structure at infiltration interface and increased water conductivity. On the other hand, with the increase of pressure head, more gravity potential energy was transformed into dynamic potential energy, making the attenuation rate of infiltration capacity slow down, so the infiltration index $\alpha$ decreased with the increase of pressure head. In practical production, the output flow of moistube irrigation can be controlled by adjusting the height of pressure head.

Increasing soil bulk density hindered water infiltration, which was basically consistent with the relevant research results $[12,20]$. In our study, it was found that infiltration index $\alpha$ increased with the increase of soil bulk density, but the cumulative infiltration, steady infiltration rate, soil wetting volume and infiltration coefficient $K$ decreased. This was because with the increase of soil bulk density, the infiltration of soil water was mainly accomplished by macropore. Therefore, the soil air permeability and water storage capacity reduced with the increase of soil bulk density, which could lead to the decrease of infiltration rate, cumulative infiltration volume and wetting volume. In addition, the smaller the gasphase ratio, the greater the infiltration resistance and the faster decline of the infiltration capacity with the higher the soil bulk density. In our study, the effects of pressure head and soil bulk density on water infiltration characteristics of vertical moistube irrigation were studied, but the effects of initial soil moisture content, burial depth, salinity, infiltration time and 
water infiltration of moistube irrigation and its impact degree need to be further studied.

\section{CONCLUSIONS}

(1) Under the vertical moistube irrigation, the soil wetting volume had a quadratic polynomial relationship with infiltration time. The soil wetting volume decreased with the increase of soil bulk density and increased with the increase of pressure head.

(2) The infiltration rate was relatively fast in the initial stage of infiltration. With the lengthening of infiltration time, the infiltration rate decreased gradually, and the infiltration rate tended to be stable around 48 hours.

(3) The infiltration rate and cumulative infiltration rate were in accordance with the power function of exponential negative and exponential positive respectively under the vertical moistube irrigation. the larger the soil bulk density, the smaller the cumulative infiltration and the infiltration rate, and the larger the pressure head, the higher the cumulative infiltration and the infiltration rate.

(4) The cumulative infiltration of vertical moistube irrigation with time conformed to the Kostiakov model, and the infiltration coefficient $K$ was negatively correlated with soil bulk density but positively correlated with pressure head, while the infiltration index alpha was positively correlated with soil bulk density but negatively correlated with pressure head.

\section{ACKNOWLEDGMENT}

This research was supported by the National Natural Science Foundation of China (Grant No. 51979133, Grant No. 51769010, Grant No. 51109102 and Grant No. 51469010).

\section{REFERENCES}

[1] Zou, X.Y., Quan, T.H., Zhou, M.N., Yang, Q.L., Shi, Y. (2017). Progress and prospects of moistube irrigation technology research. Bulletin of Soil and Water Conservation, 37(4): 150-155. http://dx.chinadoi.cn/10.13961/j.cnki.stbctb.2017.04.02 5

[2] Dou, C.Y., Meng, W.Z., Tong, W. (2014). Studies on self-suction micro irrigation regime for maize on aeolian sandy soil. Journal of Jilin Agricultural Sciences, 39(2): 13-17. http://dx.chinadoi.cn/10.16423/j.cnki.10038701.2014.02.005

[3] Quinones-Bolanos, E., Zhou, H., Soundararajan, R., Lamber, T.O. (2005). Water and solute transport in pervaporation hydrophilic membranes to reclaim contaminated water for micro-irrigation. Journal of Membrane $\quad$ Science, $252(1-2)$ : $\quad$ 19-28. https://doi.org/10.1016/j.memsci.2004.10.038

[4] Zhu, Y.X., Wang, X.K., Cheng, Y., Yang, Y.C. (2015). Research on the hydraulic performance of semipermeable membrane moistube. China Rural Water and Hydropower, 5: 23-25, 30.

[5] Liu, X.G., Zhu, Y.F., Yu, X.D., Li, Y.L., Tang, J.K., Yu, L.M. (2017). Water-salinity distribution characteristics in wetted soil of moistube irrigation under different pressure heads and soil bulk densities. Transactions of the Chinese Society for Agricultural Machinery, 48(7): 189-197. http://dx.chinadoi.cn/10.6041/j.issn.10001298.2017.07.024

[6] Xie, W.X., Qi, S.L., Liu, G.H., Wang, Y.Z., Ma, X.P. (2014). Buried moistube infiltration testing under sandy loam. Xinjiang Agricultural Sciences, 51(12): 2201-2205.

[7] Zhang, J., Niu, W.Q., Zhang, L.L., Shi, Y.L. (2012). Experimental study on characters of wetted soil in moistube irrigation. Science of Soil and Water Conservation, $10(6)$ : 32-38. https://doi.org/10.16843/j.sswc.2012.06.007

[8] Niu, W.Q., Xue, W.L. (2014). Effects of mineralization degrees on soil infiltration under moistube-irrigation. Transactions of the Chinese Society for Agricultural Machinery, 45(4): 163-172. http://dx.chinadoi.cn/10.6041/j.issn.10001298.2014.04.026

[9] Zhang, L.K, Dou, C.Y., Li, G.Y., Li, C.L. (2013). Application of self-suction micro-irrigation to baby cabbage planting in greenhouses. China Rural Water and Hydropower, (4): 53-55, 60.

[10] Koumanov, K.S., Hopmans, J.W., Schwankl, L.W. (2006). Spatial and temporal distribution of root water uptake of an almond tree under microsprinkler irrigation. Irrigation Science, 24(4): 267-278. https://doi.org/10.1007/s00271-005-0027-3

[11] Golcu, M., Pancar, Y., Sekmen, Y. (2006). Energy saving in a deep well pump with splitter blade. Energy Conversion \& Management, 47(5): 638-651. https://doi.org/10.1016/j.enconman.2005.05.001

[12] Zhang, G.X., Shen, L.X., Guo, Y.M. (2017). Effect of pressure heads and soil bulk density on water infiltration under moistube irrigation. Agricultural Research in the Arid Areas, 35(4): 67-73. http://dx.chinadoi.cn/10.7606/j.issn.10007601.2017.04.11

[13] Prunty, L., Bell, J. (2007). Infiltration rate vs. Gas composition and pressure in soil columns. Soil Science Society of America Journal, 71(5): 1473-1475. https://doi.org/10.2136/sssaj2007.0072N

[14] Furman, A., Warrick, A.W., Zerihun, D., Sanchez, C.A. (2006). Modified Kostiakov infiltration function: Accounting for initial and boundary conditions. Journal of Irrigation \& Drainage Engineering, 132(6): 587. https://doi.org/10.1061/(ASCE)07339437(2006)132:6(587)

[15] Niu, W.Q., Zhang, J., Zhang, L.L., Xue, W.L., Zhang, L.T. (2013). Effects of buried depth and pressure head on water movement of wetted soil during moistubeirrigation. Transactions of the Chinese Society for Agricultural Machinery, 44(12): 128-134. http://dx.chinadoi.cn/10.6041/j.issn.10001298.2013.12.021

[16] Xue, W.L., Niu, W.Q., Luo, C.Y., Xue, L., Wu, Z.G. (2014). Prediction model of wetted front migration distance under moistube-irrigation. Journal of Soil and Water Conservation, 28(4): 49-54. http://dx.chinadoi.cn/10.13870/j.cnki.stbcxb.2014.04.01 0

[17] Yu, X.D, Liu, X.G., Zhu, Y.F., Qi, Y.T., Yang, Q.L., Tang, J.K. (2017). Effects of soil texture and water pressure on moistube infiltration in vertical inserting mode. Journal of Drainage and Irrigation Machinery 
Engineering,

35(1):

$71-79$

http://dx.chinadoi.cn/10.3969/j.issn.1674-8530.16.0099

[18] Lv, G., Wu, X.Y. (2008). Review on influential factors of soil lnfiltration characteristics. Chinese Agricultural Science Bulletin, 24(7): 494-499.

[19] Wu, J.H., Zhang, T.G., Zhao, W., Li, J.K., Yang, L. (2013). Influence of soil bulk density on soil water infiltration characteristics under different soil organ. Journal of Soil and Water Conservation, 27(3): 63-67, 268.

http://dx.chinadoi.cn/10.13870/j.cnki.stbcxb.2013.03.02 4

[20] Li, Z., Wu, P.T., Feng, H., Zhao, X.N., Huang, J., Zang, W.H. (2009). Simulated experiment on effect of soil bulk density on soil infiltration capacity. Transactions of the Chinese Society of Agricultural Engineering, 25(6): 4045.

http://dx.doi.org/10.3969/j.issn.1002-
6819.2009.06.007

[21] Li, X.Z., Fan, G.S. (2006). Influence of organic matter content on infiltration capacity and parameter in field soil. Transactions of the Chinese Society of Agricultural Engineering, 22(3): 188-190.

[22] Liang, F.B. (2010). Method of Applied Statistics. Beijing: Peking University Press.

[23] Zhang, J., Niu, W.Q., Zhang, L.L., Sui, L.Y., Wu, G.Z. (2014). Effects of soil initial water content on line-source infiltration characteristic in moistube irrigation. Journal of Drainage and Irrigation Machinery Engineering, (1): 72-79.

[24] Ma, J.J., Sun, X.H., Li, Z.B. (2004). Effect on soil infiltration parameters of infiltration head. Journal of Irrigation and Drainage, (5): 53-55. http://dx.chinadoi.cn/10.13522/j.cnki.ggps.2004.05.014 